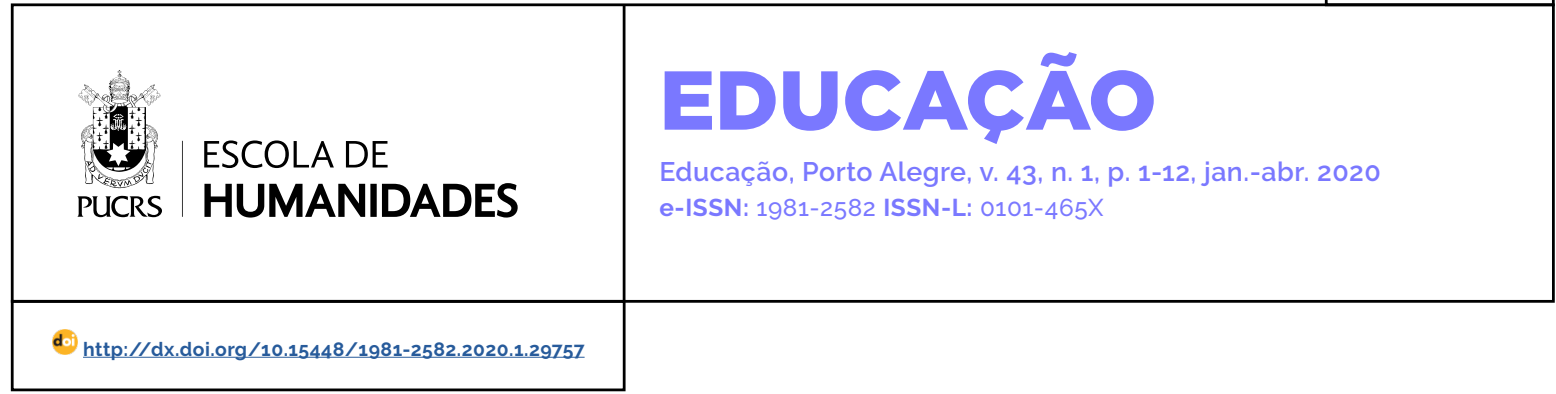

SEÇÃO: OUTROS TEMAS

\title{
Formação sem fôrma: a singularidade do processo de ser professor da Educação Infantil
}

\author{
Training without form: the singularity of the process of teaching education for children \\ Formación sin fórma: la singularidad del proceso de ser profesor de la educación infantil
}

\section{Michelle Dantas \\ Ferreira $^{1}$}

orcid.org/0000-0002-8314-1903 michaduda@yahoo.com.br

\section{Adrianne Ogêda Guedes ${ }^{1}$}

orcid.org/0000-0001-5632-4539 adrianne.ogeda@gmail.com

Recebido em: 20 jan. 2018. Aprovado em: 2 ago. 2019. Publicado em: 25 mai. 2020.
Resumo: Pesquisar sobre a formação docente ganha especial relevância nos tempos que correm. O biênio de 2016 e 2017 trouxe intensas mobilizações sociais em torno do projeto de sociedade que desejamos e o seu modelo democrático que hoje sofre um duro revés. São movimentos que impactam, necessariamente, o campo educacional. Pensar, portanto, a formação de professores, implica impreterivelmente levar em conta as forças e as pressões que esse campo está vivendo e que, ao que tudo parece indicar, continuará sofrendo. Nesse sentido, vale reafirmar com as nossas pesquisas e ações qual o professor que pretendemos formar. Diferente das perspectivas padronizadas que visam criar modelos únicos de ação, como a cultura do apostilamento, pretendemos discutir concepções de formação docente que considerem os sujeitos como autores dos seus processos formativos, pondo em destaque a potência constitutiva da Educação Estética e dos estudos voltados para as pesquisas narrativas e/ou de histórias de vida e (auto)biográficas. Palavras-chave: educação estética, formação de professores, pesquisas narrativas, pesquisas biográficas, pesquisas autobiográficas.

Abstract: Research on teacher education has gained special relevance nowadays. The biennium of 2016 and 2017 brought intense social mobilizations around the project of society that we want and its democratic model that today is suffering a severe setback. These are movements that necessarily impact the educational field. To think, therefore, the teacher training, inevitably implies taking into account the forces and pressures that this field is facing and in which, it seems, will continue to suffer. In this sense, it is worth reaffirming with our research and actions which teacher we intend to train. Different from the standardized perspectives that aim to create unique models of action, such as the booklet learnship culture, we intend to discuss conceptions of teacher education that consider the subjects as authors of their formative processes, highlighting the constitutive power of Aesthetic Education and studies focused on narrative and / or life-history and (auto) biographical research. Keywords: aesthetic education, teachers training, narrative research, research biographical, autobiographical research.

Resumen: La investigación sobre la formación docente ha adquirido especial relevancia actualmente. El bienio de 2016 y 2017 trajo intensas movilizaciones sociales en torno al proyecto de sociedad que queremos y su modelo democrático que hoy está sufriendo un grave revés. Estos son movimientos que necesariamente impactan el campo educativo. Pensar, por lo tanto, la formación de maestros, inevitablemente implica tomar en cuenta las fuerzas y presiones que este campo está viviendo y que, al parecer, continuará sufriendo. En este sentido, es fructifero reafirmar con nuestra investigación y acciones qué maestro pretendemos capacitar. A diferencia de las perspectivas estandarizadas que apuntan a crear modelos únicos de acción, como lo sistema de ensino de libros texto, pretendemos discutir las concepciones de la formación docente que consideran a los sujetos como autores de sus procesos formativos, destacando el poder constitutivo de la educación estética y de los estudios centrados en investigación narrativa y / o de historias de vida y (auto) biográfica.

Palabras clave: educación estética, formación de profesores, búsquedas narrativas, búsquedas bibliográficas, búsquedas autobiográficas. 


\section{Considerações iniciais: profissionalidade e os caminhos de se fazer professor}

As tensões atuais presentes no campo da formação docente nos exigem atenção e resistência, bem como uma postura crítica e ativa frente aos riscos que as políticas de educação correm. Freitas, em sua conferência no Encontro Nacional de Didática e Prática de Ensino (Endipe) de $2016^{2}$, sublinhou o fortalecimento da lógica tecnicista que se apresenta com novas roupagens. Lógica essa em que triunfam os princípios de racionalidade, eficiência e produtividade (Silva, 1999). Sem pretender analisar mais detidamente o complexo e polêmico panorama político do País, trazemos à baila esse assunto, para situar o contexto efervescente em que a educação se encontra e as suas consequências para o campo da formação docente, que é o foco de nosso interesse.

Acreditamos em uma formação em que os sujeitos estão no centro do processo, não apenas como atores, mas principalmente, como autores e protagonistas de suas histórias. Pensando nisso, apresentaremos inicialmente aspectos da trajetória do grupo de pesquisa ${ }^{3}$ do qual fazemos parte, constituido majoritariamente por professoras ${ }^{4}$ em exercicio e estudantes de Pedagogia, com vistas a sublinhar o lugar da autoria e da narrativa em sua constituição. Em seguida, abordaremos as proposições da Educação Estética e das narrativas autobiográficas como caminhos formativos potentes. Acreditamos que a partilha de boas experiências formativas e a reflexão crítica sobre as suas bases teóricometodológicas podem ampliar a compreensão a respeito de nossa constituição como docente.

Dessa forma, algumas perguntas se fazem necessárias e evidenciam as muitas direções que podemos tomar ao investigar essa formação docente: de que forma nos tornamos professoras?
Como as diferentes instâncias de formação colaboram nesse processo? E, nesse bojo, qual é o papel das experiências docentes? De fato, os caminhos para nos tornarmos professoras envolvem um campo extenso de experiências que vão sendo significadas pelos sujeitos de formas particulares e distintas. Caminhos que implicam dimensões objetivas e subjetivas. Aspectos que podemos acessar de forma mais evidente, como por exemplo, os conteúdos e os temas importantes na composição curricular da formação inicial de professores; outros menos visiveis e de mais dificil acesso, como aqueles que dizem respeito às experiências de vida que concorrem para sermos o que somos e se fazem presentes na forma como vemos o mundo, pensamos e agimos (Woods, 1999).

Nessa perspectiva, a temática da constituição da profissionalidade do professor emerge nas atuais tendências investigativas (Mussi \& Almeida, 2015: Sacristán, 1991; Nóvoa, 1999, 2009) sobre a docência, dando relevo também à dimensão subjetiva envolvida nesse processo e considerando a sua complexidade, que envolve levar em conta os contextos de vida e de formação dos sujeitos e os saberes que caracterizam a especificidade da vida profissional. Para Sacristán (1991), a profissionalidade docente diz respeito às especificidades exclusivas da profissão docente e, a saber, sobre a ação educativa que se constitui no próprio exercício de ser professor. Pensar o conceito de profissionalidade docente para esse autor é, portanto, levar em conta a construção que se dá na prática, que integra saberes teóricos e práticos, construidos individual e socialmente.

Desse modo, investigar o trabalho docente na perspectiva da profissionalidade envolve compreender os professores como atores sociais que, agindo em um espaço institucional dado, constroem nessa atividade, a sua vida e a sua

\footnotetext{
2 Informação verbal obtida durante o Endipe de 2016, em conferência de abertura do evento, proferida por Luiz Carlos Freitas, no dia 23 de agosto

3 O grupo Formação e Ressignificação do Educador: Saberes, Troca, Arte e Sentidos (Frestas) foi fundando em fins de 2013 e está inscrito no diretório de grupos de pesquisa da Plataforma Lattes (dgp.cnpq.br/dgp/espelhogrupo/0961910391350474). Atualmente o Frestas integra o Núcleo Infâncias, Natureza e Arte (NiNA), vinculado a Universidade Federal do Estado do Rio de Janeiro (Unirio) e tem como foco pesquisar Educação Estética, Corpo e Arte na Formação de Professores e na Educação Infantil. É coordenado pela professora Dra. Adrianne Ogêda Guedes, professora associada da instituição e possui cerca de 25 pesquisadores entre voluntários e bolsistas da graduação, extensão e ensino.

4 Ao falarmos do grupo e dos profissionais da educação no sentido mais especifico do trabalho cotidiano nas instituições que atuamos utilizaremos a palavra no gênero feminino, uma vez que, somos maioria na profissão e no grupo de pesquisa.
} 
profissão. Os professores são reconhecidos assim como atores que elaboram os sentidos e os significados sobre os seus atos e vivenciam a profissão como uma experiência pessoal, construindo os seus próprios conhecimentos e cultura própria sobre ser professor. Nóvoa (2009) adverte, no entanto, que por mais que essa profissionalidade se constitua na relação entre a formação e a prática, ela é coletiva ao passo que para que os docentes se fortaleçam profissionalmente, necessitam do espírito de coletividade e do domínio conceitual do seu ofício.

Há dificuldade em fortalecer essa coletividade docente, uma vez que existe certa hierarquia velada entre esses profissionais. Durante muito tempo, os professores das universidades estavam no topo da profissão, enquanto aqueles que trabalhavam com a Educação Básica eram vistos como os ocupantes de um posto inferiorizado e pouco valorizado, não só pela população como pelos seus pares. Esse panorama muda um pouco com a ascensão e propagação dos estudos sobre a infância, que colocam o trabalho com as crianças pequenas, principalmente da Educação Infantil, em evidência, revelando a importância de experiências ricas e vivências potentes às crianças pequenas. Entretanto, ainda há preconceito por parte de muitos acerca da indissociação entre cuidar e educar.

Apesar de parecer um tema que esgotou as suas possibilidades, essa discussão entre quem cuida e quem educa ainda rende frutos e muita cisão entre os profissionais que atuam na primeira etapa da Educação Básica. Essa diferença não fica só a nivel interpessoal, mas se concretiza quando analisamos sob o viés econômico e formativo. Um professor de Educação Infantil (PEI) no município do Rio de Janeiro recebe hoje o menor vencimento da categoria, apesar de possuir as mesmas atribuições que os outros docentes do Ensino Fundamental I. A justificativa fica a cargo do concurso prestado por esse profissional, que exigiu apenas o nivel médio - modalidade normal como grau de instrução, inferior aos outros cargos, que exigiram a graduação. Independentemente da justificativa, tanto a remuneração, o nivel de instrução exigido no concurso, quanto o número reduzido de formações em serviço ofertadas para esses profissionais dizem muito sobre as concepções de infância, criança, docente e formação defendidas pelo Município.

Ancoradas nos estudos da Educação Estética, interessa-nos nesse artigo dar relevo aos aspectos vivenciais desse professor, que concorrem para que ele vá encontrando respostas às necessidades que o cotidiano profissional apresenta. Entendemos que os saberes que se constituem na prática profissional configuramse como uma integração dos modos de pensar e agir constituidos tanto pela mobilização de conhecimentos e métodos de trabalho, como pelo impulsionamento de intenções, valores individuais e grupais, da participação e do comprometimento com a cultura institucional, que são erigidos nos percursos de vida dos sujeitos, em suas experiências estéticas.

Nesse trabalho, trazemos aspectos de um percurso de pesquisa-formação vivenciado pelo grupo de pesquisa já mencionado, com o objetivo de evidenciar os caminhos formativos que ele vem traçando e as suas consequentes escolhas epistemológicas. As pesquisas narrativas, autobiográficas e de histórias de vida, na construção de narrativas de si, nos forneceram caminhos metodológicos potentes para investigar o campo da formação docente. Somando-se a isso, os exercícios investigativos sobre as nossas próprias práticas em escolas e outras experiências e espaços educativos apresentam-se como fontes de conhecimento a respeito dos processos pelos quais passamos na constituição de nossa docência.

\section{Nas frestas, um encontro potente: construindo um caminho de pesquisa-formação}

Para os navegantes com desejo de vento, a memória é um ponto de partida. (Galeano, 1994, p. 96)

Viver poeticamente (...) acontece a partir de um certo patamar de participação, na excitação, no prazer, estado que pode ser alcançado na relação com o outro, na relação comunitária, na relação estética. É vivido com alegria, embriaguez, comemoração, gozo, vo- 
lúpia, delícia, encantamento, fervor, fascinação, beatitude, deslumbramento, adoração, comunhão, entusiasmo, exaltação, êxtase. Produz satisfação carnal e espiritual. Leva-nos a alcançar o sagrado, um sentimento que aparece no apogeu da ética e do poético. $O$ máximo da poesia, o máximo na união da sabedoria com a loucura, como o máximo da religação, é o amor. A fé ética é o amor. Mas é um dever ético proteger a racionalidade no coração do amor. Amor/racionalidade estão ligados um ao outro, é o amor que nos ensina a resistir à crueldade do mundo, que nos dá coragem, permite que vivamos na incerteza e na inquietude. É resposta para a morte, remédio para angústia. (Morin, 2007, p. 202)

Morin (2007) nos convida a considerar a potência das relações coletivas como um patamar para a vida poética. Poesia e sabedoria engendrados, potencializando a nossa existência. Relação comunitária como instância que dá sentido à existência. Essas ideias iniciais inspiramnos a apresentar alguns aspectos da história de criação do grupo de pesquisa e extensão que trazemos nesse artigo, pondo em evidência um percurso que tem sido de permanente criação, em que, escolhas epistemológicas, concepções que sustentam as investigações e as diferentes miradas vão firmando os caminhos e mobilizandonos. Interessa-nos dar relevo à concepção de formação docente que anima o grupo e que tem sido foco de suas ações de pesquisa e extensão empreendidas, desde 2014, na Universidade Federal do Estado do Rio de Janeiro (UNIRIO).

Em 2013 e 2014, algumas universidades públicas do Rio de Janeiro fizeram um convênio com o Ministério de Educação (MEC) e promoveram um conjunto de cursos de especialização e extensão voltados para professores de Educação Infantil em exercício na rede pública do Rio de Janeiro, cuja ênfase metodológica recaía sobre a necessária articulação entre as experiências dos docentes e as abordagens teóricas previstas no desenho curricular. Essa iniciativa foi uma das poucas que promoveram a articulação entre a Universidade e as escolas e apresenta caráter isolado quando o assunto é formação para profissionais da Educação Infantil, como apontam Kramer, Corsino e Nunes (2008), em suas pesquisas:
A formação oferecida pelos municipios que implementam algum projeto de formação em serviço para seus profissionais de educação infantil é desigual, predominando atividades eventuais, que tendem a descontinuidade. É bastante reduzida a participação de universidades ou faculdades públicas na formação oferecida pelos municípios Há parcerias com grupos privados, mas poucos são os projetos que habilitam os profissionais envolvidos, aspecto aqui destacado porque a habilitação é uma importante iniciativa no que se refere à qualificação, além de ser uma exigência legal. (p. 24-25)

O Curso de Extensão ofertado em 2014 concentrou-se no campo das Artes e da Infância, tendo como eixos centrais: Corpo, Arte e Natureza. Ao final do curso algumas professoras participantes procuraram a coordenação pedindo que houvesse uma continuidade no espaço de trocas e experiências proporcionado pelos encontros. Diziam ter a sensação de que o que haviam vivido e aprendido não poderia ficar apenas com elas ou restrito àquele espaço. Era preciso expandir a experiência de descobertas e inquietações e contagiar outros professores e lugares. Assim como foram atingidas pelo sopro da redescoberta de si e do outro através da educação e da arte, desejavam que esse movimento não cessasse. Esse nascedouro, já diz da especificidade desse encontro: o que move esse grupo é o desejo de parceria.

o grupo foi inicialmente constituido por professoras das escolas municipais e professoras da Universidade - e outros parceiros que posteriormente foram chegando. Houve o empenho de todas as integrantes em criar um espaço-tempo que incluísse pesquisa, experiência e troca. Aos poucos, estudantes de graduação (bolsistas de iniciação científica, extensão, ensino e voluntários), educadores de escolas, de espaços não escolares e das áreas de dança, artes visuais etc., foram se juntando ao grupo. Formações e experiências distintas iam dando um colorido especial. Em comum: a conexão/interesse com/por arte, infância e formação de professores. Desde 2014, temos empreendido pesquisas, cuja ênfase recai sobre as metodologias de formação docente. 
A proposta principal do grupo tem sido investigar a formação docente, rompendo com uma perspectiva normativa, integrando em suas ações, estudo, pesquisa e experiências - ao estilo do que haviam vivido no curso, cuja proposta teórico-prática envolvia oficinas variadas no campo das artes e do corpo. Os encontros do grupo garantem espaços de diálogo sobre as questões cotidianas vividas nas escolas e/ou outros espaços formativos em que atuam os pesquisadores e a possibilidade de vivências coletivas de experiências estéticas a partir de temas de interesse ou idas a exposições e outras atividades artísticas e culturais que estejam circulando na cidade. O objetivo é ampliar o repertório artístico cultural do grupo, bem como apurar a atenção às próprias percepções e às ações cotidianas, dando sentido a uma escuta sensivel e buscando um olhar mais afinado para o interior e para os outros a nossa volta, (re)descobrindo-nos por meio de uma formação sensivel e estética. Essas experiências vêm impactando as nossas práticas com as crianças e/ou com os adultos, gerando uma escuta mais atenta e dando mais visibilidade ao corpo, às artes e à relação com a natureza em nossas práticas docentes.

Esse acesso aos bens culturais, apesar de fundamental na constituição da profissionalidade desse ser professor de Educação Infantil, não ocorre de forma igualitária entre todos os docentes. Kramer (2008, p. 25) mostra em sua pesquisa que "os contextos cultural e científico em que se dá a formação dos profissionais de educação infantil têm lacunas, e a educação como parte de um projeto cultural mais amplo sofre restrições". Isso significa que além de formações que visem ampliar o conhecimento específico desses profissionais, faz-se urgente também fomentar um alargamento em seu repertório cultural e artístico. Possibilitar a existência, diversidade de instituições e acesso à museus, centros culturais, cinema, teatro, parques, livrarias, bibliotecas é dever do Estado e direito dos indivíduos, que nem sempre é garantido e incentivado.

Outro ponto delicado é a inferiorização dos profissionais que lidam com a primeira infância, principalmente os bebês - considerados aqui as crianças que têm até dois anos de idade - e as crianças pequenas - de 3 a 5 anos -, que constituem a Educação Infantil. O professor da infância ainda é muito estigmatizado como aquele que tem um conhecimento de menor importância, que ganha para realizar cuidados que qualquer pessoa poderia fazer. Isso porque ainda há forte preconceito e tensão no reconhecimento do cuidado como momento de construção de conhecimento.

Esse caldo de experiências e trocas têm sido o combustivel a fomentar nossos questionamentos: como se forma o professor? De que maneira a formação inicial e continuada pode envolver a Educação Estética? O que as experiências mobilizam? Como elas reverberam transformandose em conhecimento? De que forma ajudam a construir a identidade docente de cada um de nós? Pensar a formação dos professores, as questões da infância, o lugar do corpo nas relações e o que constitui a docência na Educação Infantil são as questões centrais que mobilizam, unificam e também dão identidade a todos nós.

Pesquisa-formação e pesquisa coletiva: metodologias de um grupo de pesquisa

O primeiro passo do grupo foi fundamentar e referenciar os conceitos com os quais gostariamos de trabalhar, tais como: Educação Estética/Educação do sensivel, vivência, experiência, metodologias de pesquisa e formação docente. A autoria no processo de formação do professor (Longarezi, 2013) e as pesquisas narrativas, autobiográficas/biográficas e de histórias de vida (Chaves, 2000; Josso, 2004: Souza, 2007) têm sido referências teóricas centrais. Consideramos esses temas essenciais e temos nos dedicado a estudá-los. A partir desses estudos realizamos o que chamamos de exercícios investigativos: selecionamos uma experiência ou questão do cotidiano dos pesquisadores para examinar, tendo nossas perguntas como impulsionadoras e os conceitos que norteiam nossas discussões como chaves interpretativas.

Desse modo, as pesquisas que empreendemos mantêm um caráter de construção coletiva em que há uma permanente retroalimentação entre 
as experiências advindas da prática docente e o campo teórico (Longarezi, 2013). Os exercícios investigativos relatados anteriormente se dão a partir dos registros de nosso cotidiano, seja ele escolar, - e aqui nos referimos às instituições nas quais trabalhamos - pessoal ou institucional - atribuidos aos espaços de formação que frequentamos. Dessa forma, ao contemplar uma brincadeira vivida, perceber as descobertas infantis, suas conquistas, os entraves cotidianos; nas visitas a exposições e eventos ou nos textos lidos e vídeos assistidos, esses escritos dão visibilidade ao que nos impulsiona, desperta e mobiliza, possibilitando que sejamos professoras pesquisadoras, investigando e vivenciando de forma ativa essa construção.

Valorizamos esses registros como forma de reflexão e discussão entre nós e os utilizamos como ferramenta que dá visibilidade às nossas narrativas. Assim, fazemos dela um recurso para analisar a prática profissional na construção do conhecimento, ressignificando a própria prática. A narrativa faz parte de nós, nos constitui, além de ser um campo ricamente empirico, colocando em exercicio as nossas reflexões, escritas e perspectivas. Ressaltando que ao revisitar, narrar e compartilhar, esses registros são mais que recordações: são fonte de pesquisa, documentação e formação.

As narrativas formam um vigoroso material, pois nos ajudam a compreender os processos de formação, as identidades e as aprendizagens, percebendo as tessituras e os conhecimentos, integrando a coletividade e a subjetividade, que nos levam a investigar e a ressignificar de forma contextualizada o nosso próprio percurso, trazendo, muitas vezes, o que está escondido ou que passaria despercebido e, assim, pouco a pouco, as memórias vão ganhando vida. Josso (2004, p. 9), corrobora com essa ideia ao afirmar que as narrativas favorecem a autoformação e a autorreflexão de forma a "explicitar a singularidade e, com ela vislumbrar o universal, perceber o caráter processual da formação e da vida, articulando espaços, tempos e as diferentes dimensões de nós mesmos, em busca de uma sabedoria de vida".
Desse modo, destacamos a potência das narrativas e autobiografias, pois somos sujeitos únicos, constituintes e instituintes de história, escolhas e ações, considerando a nossa trajetória de vida e profissional, os nossos saberes, a nossa construção de conhecimento e as nossas experiências. Ao escrevermos sobre nós, relatando as nossas experiências, estabelecemos um diálogo com os interlocutores, expressando nossos múltiplos "eus" (Larrosa, 1998).

As autorias nos permitem compreender as diversidades, olhar por ângulos diferentes um mesmo ponto, e propõem, aos que têm contato com elas, refletir sobre as próprias trajetórias.

A beleza de resgatar as histórias das
pessoas, o desafio que esse resgate
traz, está em encontrar, olhar, compre-
ender como a história mais ampla se
impregna e constitui as pequenas his-
tórias individuais e coletivas, as infimas
situações, os fragmentos de práticas
que precisam ser conhecidas. (Kramer,
Corsino, \& Nunes, 2008, p. 65)

Trabalhamos, assim, com a metodologia de pesquisa coletiva, que passou a existir a partir de outros dois modelos de investigação qualitativa: a pesquisa-ação e a pesquisa participante (Alvarado-Prada, 2005). De acordo com o autor colombiano, esse tipo de investigação compartilha com a metodologia da pesquisaação a preocupação com relação à transformação da realidade, se dispondo também a descobrir como os participantes processam a dinâmica da vivência em grupo; bem como a forma direta de desenvolver ações transformadoras a partir da investigação de situações-problema, gerando transformações. Trata-se de um tipo de pesquisa que tem sido desenvolvido em projetos de formação continuada de professores e se caracteriza por considerar a horizontalidade nas relações entre os participantes, incluindo quem orienta ou propõe a pesquisa. Os objetos de pesquisa são construídos pelo coletivo, dependendo da especificidade das questões de interesse, conhecimento e experiência dos participantes, ou seja, "a discussão e a elaboração dos objetivos [são] baseados numa concepção 
de educação que não seja imposta de cima para baixo, mas fruto de uma construção coletiva enraizada na própria prática docente" (Kramer, Corsino, \& Nunes, 2008, p. 20). O coletivo constrói e interage na construção dos dados da pesquisa e na análise e sistematização dos mesmos. Nesse modelo, são os participantes que intervêm na produção do conhecimento, que se dá de forma coletiva e com a utilização dos conhecimentos derivados das experiências, das vivências, das elaborações internas e sociais de cada um, pois como diz Naspolini (citado por Kramer, 2008, p. 20) "tornar os sujeitos autônomos sem submissão de uns a outros supõe modos de articulação em que todos sejam capazes de fazer opções conscientes e consentâneas aos seus interesses".

O caráter formativo da pesquisa coletiva se constitui pelos inúmeros processos que envolvem construção e reconstrução dos dados, gerando reflexão e análise da realidade, bem como consensos entre os participantes. A valorização do saber de todos os componentes é crucial, e as experiências cotidianas e práticas no confronto com os chamados conhecimentos "cientíicos" fomentam a construção de novos conhecimentos. Isso caracteriza a pesquisa coletiva como uma pesquisa-formação, pois nesse processo o professor se desenvolve profissionalmente, tomando a sua prática de ensino para as construções coletivas.

Essa apresentação da constelação de ideias e conceitos que norteiam o grupo ao qual pertencemos têm como objetivo central dar destaque ao processo formativo que está presente no próprio ato de se constituir como pesquisadora e professora. Nossa identidade docente, a forma como temos aprendido a ser professoras em exercício, tem incluido a experiência coletiva de pesquisar sobre as nossas práticas e os nossos percursos, em diálogo com teorias que nos instigam a abordar por diferentes ângulos os temas que temos elegido. Autores como Ostetto (2012, 2014, 2016); Kramer, Nunes, \& Carvalho (2013); André (2012); Tardif (2014); Schön (2000); Tardif, \& Lessard (2014a, 2014b) compõem, junto com os já citados anteriormente. o embasamento teórico-epistemológico que norteia nossas pesquisas sobre a formação docente e profissionalidade do professor.

\section{Formação de professores: por uma Educação Estética}

Tomando as concepções expostas até aqui, afirmamos a concepção de formação docente como um processo que inclui sujeitos autônomos, que precisam ser considerados como construtores de conhecimento, cuja experiência precisa ser reconhecida, valorizada e mobilizada nas ações formativas; profissionais que reconheçam as suas funções e estejam cientes das relações que estabelecem nas instituições educacionais e que tenham clareza das suas intenções no processo de conhecimento. Defendemos uma formação que coloque o professor no centro do processo, aparecendo como protagonista e autor de sua própria história e que cuide não só da razão, mas também, e principalmente, da emoção e das sensibilidades. Somos seres inteiros. No entanto, viemos sendo fragmentados desde o lluminismo, onde a razão e a ciência passam a ser o centro do poder e da intelectualidade.

O movimento iluminista, forjado no trabalho reflexivo de inúmeros filósofos, postulava a supremacia da razão humana face a explicações miticas e religiosas da existência. Eleita a primordial dentre as faculdades humanas, a razão devia ser devidamente educada e desenvolvida, a fim de que a humanidade pudesse caminhar (utopicamente) em direção à sua maioridade, ou seja, rumo a uma vida plena de conhecimentos estabelecidos racional e cientificamente, até que se chegasse numa existência liberta de quaisquer peias irracionais (...) Mais do que nunca, está-se num tempo no qual a confiança na racionalidade humana é indiscutivel. (Duarte-Junior, 2000, p. 50)

O resultado disso é a dificuldade de conexão entre os individuos, que vivem compartimentalizados, o que só se agrava em uma sociedade que funciona em um ritmo cada vez mais acelerado. Não temos tempo para as relações, para o outro e nem para nós mesmos. Vivemos de automatismos, não conseguindo apreciar, sentir, experimentar os acontecimentos 
que nos atravessam como raios em dias de tempestade. A aprendizagem, dessa forma, transforma-se em mero acúmulo de informações, pois não há tempo para a reflexão nem para a decantação do pensamento.

A Educação Estética, que defendemos, vem totalmente à contrapelo, parafraseando Benjamin (1987), ou seja, preconiza que as vivências devem acontecer também com o educador, uma vez que só pode promover uma educação sensivel quem tem ou teve essa sensibilidade aguçada em algum momento da vida. Concordamos com Duarte-Junior (2010, p. 31) ao dizer que "uma educação do sensivel só pode ser levada a efeito por educadores cujas sensibilidades tenham sido desenvolvidas e cuidadas".

Pensamos em estética como aquilo que nos atravessa, nos toca, independentemente do conceito do que seja o belo, muito atrelado a ela. A Educação Estética vem por meio dos sentidos, que passam a estar mais atentos aos acontecimentos que perpassam pelo corpo, afinal, "nossa história se inscreve em nosso corpo e os movimentos são reflexos de emoções e sentimentos" (Vianna citado por Resende, 2008, p. 564). Ela, então, é tomada aqui como algo visceral, ou seja, que vem de dentro ou que nos atinge por dentro, despertando e/ou aguçando sentidos, nos atravessando e afetando. Por isso é independente da arte, embora tenha grande afinidade com ela. Para isso, não faz sentido que as formações tenham o formato prescritivo, onde um grupo de pessoas está ali para transmitir conhecimentos como se fossem receitas prontas e o outro para receber, perpetuando a famosa educação bancária criticada por Paulo Freire.

Seguimos com Freire por gostarmos bastante do olhar que o educador traz sobre a estética como algo que acontece na realidade, nas relações, na escola, na sala de aula e na relação entre as crianças e o professor. Para ele, o gestual, o tom de voz e a forma como conduz a sua turma, fazem parte de uma estética da sala de aula. Percebemos a sua importância na fala do autor, quando diz que "é impossivel educar sem fazer uma experiência estética" (Freire citado por Trezzi, 2011, p. 74). A formação de professores, então, é um momento de educar com o corpo inteiro, de vivenciar experiências em que razão e emoção estão imbricadas, em uníssono, como a criança quando brinca que, ao mesmo tempo em que fantasia, vive uma realidade a fim de compreendêla, experimentá-la, processá-la em seu interior.

Como já foi dito, para que esse professor tenha essa formação estética, deve abrir-se à experiência do sensivel. Não só com relação às crianças, mas a si mesmo, afinal, o estético reside nas vivências e no que fazemos com elas. Nesse sentido, a aprendizagem é vista como "afetamento", tornando-se um acontecimento estético por passar pelos sentidos, atravessar as emoções e estar presente nas relações.

Defendemos que uma formação estética requer olhares, escutas, falas, disponibilidade para o outro; vontade de se expressar verdadeiramente e acolhimento para receber o que se expressa, sem julgamentos, valores, pudores; sempre afetando de alguma forma, deixando marcas que, muitas vezes, são sentidas no mais profundo silêncio e que se expressam em um gesto, em um toque, em um olhar.

Acreditamos, então, em uma formação pautada em vivências. Não queremos dizer com isso que qualquer proposta é uma vivência. Substituir aulas por vivências não significa retirar o que chamamos de teoria, mas, pelo contrário, experimentar a teoria na prática, percebendo seu imbricamento. Tampouco significa dizer que meramente reproduziremos situações que ocorrem no interior das escolas. A ideia é construir junto aos professores momentos de exercício de sua autoria, em que contem e vivam as suas histórias de corpo inteiro, estando disponiveis para vivenciarem tantas outras. Ao fazerem isso, estarão experimentando com o corpo todo, aprendendo de maneira profunda e duradoura e esse aprendizado fica, por estabelecer fortes conexões com o emocional e não só com a razão.

Essa formação vivencial dialoga com as múltiplas linguagens que constituem os sujeitos, pois temos que considerá-los no todo. A arte aparece, então, como forte aliada, tanto no que se refere à sensibilização, quanto à ampliação de repertórios. Como já dissemos, não estamos interessadas na dimensão estética da arte que 
persegue o belo, mas na multiplicidade de diálogos que podemos travar com a música, a dança, a literatura, as artes plásticas e visuais, o teatro, as brincadeiras populares etc. É por meio das experiências que vivenciam com o corpo que as suas ações vão se enchendo de significados e de intencionalidades que vão sendo percebidas, apreciadas e levadas à reflexão, sempre com um tempo para que sejam "digeridas". Desta forma, concordamos com Larrosa (2014) que:

A experiência, a possibilidade de que algo nos aconteça ou nos toque, requer um gesto de interrupção, um gesto que é quase impossivel nos tempos que correm: requer parar para pensar, parar para olhar, parar para escutar. pensar mais devagar, olhar mais devagar, e escutar mais devagar; parar para sentir, sentir mais devagar, demorar-se nos detalhes, suspender a opinião, suspender o juizo, suspender a vontade, suspender o automatismo da ação, cultivar a atenção e a delicadeza, abrir os olhos e os ouvidos, falar sobre o que nos acontece, aprender a lentidão, escutar aos outros, cultivar a arte do encontro, calar muito, ter paciência e dar-se tempo e espaço. (p. 25)

Vale aqui retomar o valor das narrativas, anunciado quando nos referirmos à pesquisaformação, metodologia de funcionamento do nosso grupo. Ao falar de si e de seus processos, de sua história de vida e/ou dos caminhos que percorreu, essa professora não só está tendo a oportunidade de ressignificar a sua prática, refletindo e aprendendo com ela, como também está tendo a oportunidade de reafirmar o seu protagonismo como sujeito potente e criador. Além disso, ao falar de suas experiências com as crianças está ao mesmo tempo investigando e se formando, pois uma ação retroalimenta a outra, havendo aprendizado tanto na atividade quanto em sua pesquisa, uma vez que "a narrativa é tanto um fenômeno quanto uma abordagem de investigação e formação porque parte das experiências e dos fenômenos humanos advindos das mesmas" (Souza, 2007, p. 5).

Nas narrativas, vemos a história do docente sendo entremeada e escrita pelas vivências formativas que vai tendo ao longo de sua trajetória, bem como as relações que vai estabelecendo com as crianças e os adultos que convive. A memória é o fio que conduz essas narrativas, tecendo as tramas, enredando atores e costurando os acontecimentos. É latente o seu sentido como construção social e coletiva gerando aprendizagem na medida em que os indivíduos interagem com os diferentes grupos sociais.

Fica claro que ainda predomina a ideia de que o que falta aos professores e o que os qualificaria seria um conjunto de técnicas, métodos ou outras panaceias. Nesse sentido, uma proposta de formação pautada nas vivências e saberes do professor, ainda parece causar profundo estranhamento e recusa.

Compreendemos a importância da articulação entre as atividades propostas, a interação dos professores, o aguçar das sensibilidades e a presença da afetividade, que precisa permear todo o percurso formativo. Por isso, acreditamos que não há como apreender algum conhecimento, sem senti-lo. A aprendizagem começa no corpo, passa por ele, se processa por meio dele, e é aí que a necessidade do vivencial está pautada e garantida. Acreditamos que isso se faz mais do que necessário, se faz urgente na realidade dos espaços escolares, principalmente de Educação Infantil, onde nos deparamos com corpos precarizados, instituidos e diariamente violentados, tanto dos educadores quanto das crianças, como nos mostram pesquisas, como as de Arroyo (2012).

Apostamos em uma formação que proporcione outros modos de encontro entre o corpo, a teoria e a prática no campo da educação. Nesse modelo, o professor não é mero expectador, que colhe receitas prontas, mas alguém que se constitui em meio a experiências que primam pela instigação de sua sensibilidade, pelo "afetamento" do encontro com seu "eu" e dele com o(s) outro(s) (Woods, 1999), pois concordamos com Fischer (citado por Loponte, 2011):

Além de um lugar de lamentação e impossibilidades diárias, a docência pode ser lugar mesmo de onde talvez seja possivel não exatamente pensar nossos limites e as forças que nos constrangem, mas as condições e possibilidades infindas, imprevisiveis e indefinidas de nos transformarmos e de sermos diferentes do que somos. (p. 42-43) 
Esse tipo de formação nos traz então um entrelaçamento entre escola, universidade, professores, discentes, individual, privado e coletivo, costurando por meio da afetividade e das vivências uma rede de (des)encontros, conquistas, reflexões, onde o centro é a busca por uma educação mais viva, afetiva, próxima da criança e que está intimamente ligada aos processos formadores dos profissionais que com elas atuam. Para que esse professor tenha essa formação estética, deve abrirse à experiência do sensivel. Não só com relação às crianças, mas a si mesmo.

Enfim, sabemos o quão difícil é falar de uma educação das sensibilidades, principalmente em uma sociedade que necessita de provas cientificas, empiricas que definem exatamente, meticulosamente e invariavelmente "o quê" e "como" aquilo que está sendo estudado acontece. Nesse caso, no entanto, não há como provar inteiramente, cientificamente o que acontece, quando nos propomos a fazer uma Educação Estética, pois em cada indivíduo reverberará de uma forma e não há certo ou errado nisso. O mais importante é que reverbere, que dê sentido, que traga a consciência do que somos em essência, pois permite uma verdadeira alteração da realidade. E é disso que tratamos e queremos, quando propomos que as formações de professores busquem novos caminhos do fazer, olhando mais para dentro do que para fora e enaltecendo os seres humanos naquilo que há de mais bonito, sua singularidade e inteireza de ser.

\section{Considerações finais: a construção da profissionalidade do professor da Educação Infantil}

Falar em formação do profissional que atua na Educação Infantil é pisar em solo sensivel, pois poucas são as formações específicas para os docentes que atuam nesse nivel, principalmente na cidade do Rio de Janeiro. Os cursos de Pedagogia trazem uma noção básica acerca da sua história, apresentando os principais documentos que a norteiam e concepções que a fundamentam, porém não dão conta - e cremos que o seu objetivo não seja realmente esse - das especificidades, das minúcias que a caracterizam. Ao mesmo tempo, não há um investimento público em formações voltadas para os profissionais que atuam nas escolas. Poucos são os cursos e eventos e ainda mais raras são as ações que incentivam a participação dos docentes que atuam na Educação Infantil. Os que aparecem tendem a trazer uma concepção de criança como um ser incompleto, que está se preparando para "vir a ser alguém" no futuro. Nessa visão, a Educação Infantil prioriza a falta e foca em uma preparação para os segmentos posteriores. Isso influencia na visão que se constrói acerca dos profissionais que atuam nessa etapa de ensino. Não é raro que "as meninas"5 da Educação Infantil, ou as "tias" mencionadas por Paulo Freire, sejam vistas por seus pares - que atuam em outros segmentos -, pela gestão, pelos responsáveis e pela sociedade em geral, como sujeitos que desempenham funções menores, inferiores, que teoricamente não necessitam de formação especifica, como por exemplo, dar banho, trocar fralda e brincar. Não é à toa que as discussões expostas anteriormente sobre o binômio educarcuidar estejam sempre presentes e culminem na profissionalidade desse docente. Esses pontos refletem na concepção de identidade e valorização desses profissionais que, muitas vezes, acabam reforçando esse tipo de comportamento em suas ações no cotidiano da escola e nos discursos que proferem sobre a sua realidade.

Muitas são as questões que surgem quando se trata desse grupo de profissionais que têm tantas especificidades e particularidades. As pesquisas vêm para trazer estranhamento ao que parece normal (Kramer, 2008), inquietar e suscitar reflexões que possibilitem uma mudança nos discursos, contextos e realidades. Para nós, a Educação Estética é uma concepção passivel de proporcionar uma alteração de maneira concreta, por propor uma percepção aguçada do que está ao redor, do sentido e do vivido por todos que estão envolvidos no processo. As

5 Termo trazido por Kramer (2008) em sua pesquisa sobre os profissionais que atuam na Educação Infantil e que foi discutido ao longo do capitulo intitulado "Na gestão da educação infantil, nós temos meninas no lugar de professoras?". 
experiências vivenciadas e narradas promovem uma conscientização e uma clareza acerca do lugar ocupado e, consequentemente, de onde se quer chegar, o que não só amplia o repertório como também instiga a busca por referenciais teórico-práticos que influenciam diretamente em sua formação e podem acontecer cotidianamente quando estamos desempenhando as nossas funções junto com as crianças.

Ao longo desse artigo tentamos mostrar que a profissionalidade do sujeito não tem seu nascedouro nas Universidades e muito menos encerra-se depois da graduação concluida. A profissionalidade vai sendo construída ao longo da vida e agrega não só os conhecimentos acadêmicos como as experiências cotidianas dentro e fora da escola, no caso dos professores. Todas as vivências que nos constituem como sujeitos influenciam diretamente no profissional que nos tornamos, daí a importância do professor ser autor, protagonista de sua história. Decorre dessa mesma ideia a importância de mantermos acesos e circulantes os nossos percursos de vida, que contam muito de nós e do profissional que somos, fazendo-nos refletir a todo o instante sobre o lugar que ocupamos na escola e assumimos na formação das crianças com as quais atuamos. Afinal, não ocupamos também um lugar de referência para pessoas que estão em formação? E a forma como atuamos, essas referências que trazemos e as relações que estabelecemos não são matérias-primas para a construção de nossa profissionalidade?

Cremos que sim! Por isso, trazemos como base as narrativas autobiográficas e a Educação Estética, pois a partir das histórias de vida, das vivências que sensibilizam e dos conhecimentos construidos, o professor se reinventa e, consequentemente, traça novos caminhos em sua profissionalidade.

\section{Referências}

Alvarado-Prada, L. E. (2005). Pesquisa coletiva como um caminho na formação e professores. In Anais do $3^{\circ}$ Encontro de Pesquisas em Educação da Universidade de Uberaba (pp. 626-637). Uberaba, MG.
André, M. (Org.). (2012). O papel da pesquisa na formação e na prática dos professores (Série Práticas Pedagógicas, 12a ed.). Campinas, SP: Papirus.

Arroyo, M. (2012). Corpos precarizados que interrogam nossa ética profissional. In M. R. Silva \& M. Arroyo (Orgs.). Corpo-infância: exercícios tensos de ser criança; por outras pedagogias dos corpos (pp. 23-54). Petrópolis, RJ: Vozes.

Benjamin, W. (1987). Obras escolhidas I: magia e técnica, arte e política. São Paulo: Brasiliense.

Chaves, I. (2000). A pesquisa narrativa: uma forma de evocar imagens da vida de professores. Revista Educação em Debate, 1(39), 86-93.

Duarte-Junior, J. F. (2000). O sentido dos sentidos: a educação (do) sensivel (Tese de Doutorado). Faculdade de Educação, Universidade Estadual de Campinas, Campinas.

Duarte-Junior, J. F. (2010). A montanha e o video-game: escritos sobre a educação. São Paulo, SP: Papirus.

Galeano, E. (1994). Palavras Andantes. Porto Alegre, RS: L\&PM.

Josso, M. C. (2004). Experiências de Vida e Formação (J. Claudino \& J. Ferreira, Trad.). São Paulo, SP: Cortez.

Kramer, S. (2008a). Histórias de formação: as entrevistas, seu contexto e procedimentos. In S. Kramer (Org.). Profissionais de educação infantil: gestão e formação (pp. 22-36). São Paulo, SP: Ática.

Kramer, S. (2008b). Na gestão da educação infantil, nós temos meninas no lugar de professoras? In $\mathrm{S}$. Kramer (Org.). Profissionais de educação infantil: gestão e formação (pp. 121-129). São Paulo, SP: Ática.

Kramer, S., Corsino, P., \& Nunes, M. F. R. (2008a). Educar e cuidar: muito além da rima. In S. Kramer (Org.). Profissionais de educação infantil: gestão e formação (pp. 55-86). São Paulo, SP: Ática.

Kramer, S., Corsino, P., \& Nunes, M. F. R. (2008b). Formação de profissionais da educação infantil: um desafio para as políticas municipais. In S. Kramer (Org.). Profissionais de educação infantil: gestão e formação (pp. 16-36). São Paulo, SP: Ática.

Kramer, S., Nunes, M. F. R., \& Carvalho, M. C. (Orgs.). (2013). Educação Infantil: formação e responsabilidade. Campinas, SP: Papirus.

Larrosa, J. (1998). Pedagogia profana: danças, piruetas e mascaradas. Porto Alegre, RS: Contrabando.

Larrosa, J. (2014). Tremores: escritos sobre experiência Belo Horizonte, MG: Autêntica.

Loponte, L. G. (2011). Arte e inquietudes estéticas para a educação. In M. C. P. Passos, \& R. M. Ribes (Orgs). Educação: experiência estética (pp. 30-51). Rio de Janeiro, RJ: Nau.

Longarezi, A. M. (2013). Pesquisa-formação: um olhar para a sua constituição conceitual e política. Revista Contrapontos, 13(3), 214-225. https://doi. org/10.14210/contrapontos.v13n3.p214-225 
Morin, E. (2007). O método 6: ética. Porto Alegre, RS Sulina.

Mussi, A. de A., \& Almeida, E. C. dos S. Profissionalidade docente: uma análise a partir das relações entre os professores e o contexto de trabalho no ensino superior. In Anais da 37a Reunião Nacional da ANPED da Universidade Federal de Santa Catarina (pp. 4-8).

Florianópolis, SC. http://37reuniao.anped.org.br/wpcontent/uploads/2015/02/Trabalho-GT08-4324.pdf

Nóvoa, A. (Org.). (1999). Profissão Professor (Coleção Ciências da Educação). Portugal: Porto.

Nóvoa, A. (2009). Para uma formação de professores construída dentro da profissão. Revista de Educación 350, 203-218. http://WWW.revistaeducacion.educacion.es/re350/re350_ogpor.pdf

Ostetto, L. E. (Org.). (2012). Educação Infantil: saberes e fazeres da formação de professores (Coleção Ágere). Campinas, SP: Papirus.

Ostetto, L. E. (2014). Danças Circulares na formação de professores: a inteireza de ser na roda. Florianópolis, SC: Letras Contemporâneas.

Ostetto, L. E. (2016). Formação de consumidores ou criadores? Cultura e arte na Educação Infantil. In M Reis \& R. R. Borges (Orgs.). Educação Infantil: Arte, Cultura e Sociedade. (pp. 315-336). Curitiba, PR: CRV.

Resende, C. (2008). O que pode um corpo? O método Angel Vianna de conscientização do movimento como um instrumento terapêutico. Physis: Revista de Saúde Coletiva, 18(3), 563-574. https://doi org/10.1590/S0103-73312008000300011

Sacristán, J. G. (1991). Consciência e ação sobre a prática como libertação profissional dos professores. In A. Nóvoa (Org.). Profissão professor (pp. 63-92). Portugal: Porto.

Schön, D. A. (2000). Educando o profissional reflexivo: um novo design para o ensino e a aprendizagem (R. C Costa, Trad.). Porto Alegre, RS: Artmed.

Silva, C. S. B. da. (1999). Curso de pedagogia no Brasil: História e identidade. Campinas, SP: Autores Associados.

Souza, E. C. (2007). História de vida e práticas de formação: escrita de si e cotidiano escolar. In E. C. Souza (Org.). Histórias de Vida e Formação de Professores. Boletim Salto para o Futuro, mar., 3-7.

Tardif, M. (2014). Saberes docentes e formação profissional (17a ed.). Petrópolis, RJ: Vozes.

Tardif, M., \& Lessard, C. (2014a). O oficio de professor: história, perspectivas e desafios internacionais (L. Magalhães, Trad.; 6. ed.). Petrópolis, RJ: Vozes.

Tardif, M., \& Lessard, C. (2014b). O trabalho docente: elementos para uma teoria da docência como profissão de interações humanas (J. B. Kreuch, Trad.; ga ed.). Petrópolis, RJ: Vozes.

Trezzi, Cl. (2011). Schiller e Freire: um olhar sobre a educação estética. Revista Eletrônica de Ciências da Educação, 10(1), 68-77.

Woods, P. (1999). Investigar a arte de ensinar. Portugal: Porto.

\section{Michelle Dantas Ferreira}

Professora de Educação Infantil. Diretora Adjunta no Município do Rio de Janeiro, vinculada à Secretaria Municipal de Educação (SME). Mestranda em Educação na Universidade Federal do Estado do Rio de Janeiro (Unirio) e pesquisadora do grupo Frestas (Formação e Ressignificação do Educador: Saberes, Troca, Arte e Sentidos), vinculado ao Núcleo Infância, Natureza e Arte (NINA) na mesma Universidade.

\section{Adrianne Ogêda Guedes}

Professora Associada à Universidade Federal do Estado do Rio de Janeiro (Unirio), atuando na graduação dos cursos de Pedagogia presencial e a distância e no Programa de Pós-Graduação em Educação - Mestrado/ PPGEDU da Unirio. Coordenadora do grupo Frestas (Formação e Ressignificação do Educador: Saberes, Troca, Arte e Sentidos), vinculado ao Núcleo Infância, Natureza e Arte (NINA) da mesma Universidade.

\section{Endereço para correspondência}

Michelle Dantas Ferreira

Rua Antônio Storino, 126 apt. 101

Vila da Penha, 21221-460

Rio de Janeiro, RJ, Brasil

Adrianne Ogêda Guedes

Rua Luis Catanhede, 80 apt. 301

Laranjeiras, 22245-040

Rio de Janeiro, RJ, Brasil 